\title{
Bernard Lahire. L'homme pluriel. Les ressorts de l'action, Paris, Nathan, 1998, 145 F.
}

Jean Philippe Turpin

\section{OpenEdition}

1 Journals

Édition électronique

URL : http://journals.openedition.org/corpsetculture/657

DOI : 10.4000/corpsetculture.657

ISSN : $1777-5337$

Éditeur

Association Corps et Culture

Édition imprimée

Date de publication : 1 juin 1999

ISSN : 1268-5631

Référence électronique

Jean Philippe Turpin, «Bernard Lahire. L'homme pluriel. Les ressorts de l'action, Paris, Nathan, 1998, 145 F. », Corps et culture [En ligne], Numéro 4 | 1999, mis en ligne le 12 octobre 2007, consulté le 21 septembre 2020. URL : http://journals.openedition.org/corpsetculture/657 ; DOI : https://doi.org/ 10.4000/corpsetculture.657

Ce document a été généré automatiquement le 21 septembre 2020.

(c) tous droits réservés 


\title{
Bernard Lahire. L'homme pluriel. Les ressorts de l'action, Paris, Nathan, 1998, $145 \mathrm{~F}$.
}

\author{
Jean Philippe Turpin
}

1 Bien que cet ouvrage ne soit pas vraiment récent (mai 1998), il convient que les STAPS en aient connaissance. Non qu'il parle précisément d'activité sportive, mais il offre un cadre de pensée tout à fait stimulant à qui souhaite s'intéresser au phénomène central de l'action humaine. Il est en effet étonnant que depuis la théorie de l'action motrice de Parlebas, notre champ, si familier du mouvement, de l'activité, de la mise en jeu corporelle, n'ait plus affronté sérieusement le problème de l'action. Or, il paraît évident qu'elle est au centre de toute pratique physique et qu'elle peut constituer un objet dont la valeur heuristique est propre à effacer un certain nombre de doutes, qui pourraient naître ici où là de l'étroitesse de pensée dont fait souvent preuve la recherche actuelle au sein des UFRSTAPS.

Bernard Lahire prend des distances. Premièrement avec la rupture théorie/travail de terrain. S'il offre un cadre de réflexion, l'auteur se défend de proposer un texte théorique au sens où une théorie a souvent la prétention de «couvrir la totalité du monde social et faire face à tout problème à l'aide des mêmes réponses ». Pour l'auteur, chaque théorie n'est valable que rapportée aux phénomènes qu'elle décrit et les auteurs gagneraient à confronter leurs modèles afin d'en accepter les limites de validité et faire progresser la connaissance du monde social. «Les chercheurs en sciences sociales ont toujours partiellement tort de ne pas voir en quoi leur adversaires ont partiellement raison ».

Distance avec les théories de l'action ensuite. Celles-ci voient s'opposer ceux qui privilégient l'unicité et l'homogénéité de l'acteur et ceux qui plaident pour une fragmentation infinie de ses rôles. Bernard Lahire propose de questionner les conditions socio-historiques qui rendent possible un acteur pluriel ou un acteur caractérisé par une profonde unicité. On s'aperçoit alors que l'acteur est inévitablement porteur d'une pluralité de dispositions, produites par l'hétérogénéité 
des expériences vécues. Sans remettre en cause les théories dispositionnelles telles que celle de l'habitus, Lahire affirme en même temps que l'individu est toujours confronté à des situations qui viennent provoquer une rupture avec ce qui a été incorporé jusque là. Homme pluriel donc, qui n'agit que par ajustements successifs entre son être vécu et le contexte auquel il est confronté.

4 La réflexion de Lahire le conduit à proposer le programme d'une «sociologie psychologique » qui vise, tout en gardant une méthode véritablement sociologique à " étudier la réalité sociale sous sa forme individualisée, incorporée, intériorisée. »

5 «Comment la diversité extérieure est-elle faite corps? comment peut-elle habiter le même corps? " Vaste programme dans lequel une recherche sur l'action corporelle comme produit complexe de multiples processus de socialisation aurait naturellement sa place... 